\title{
A Diretiva Europeia sobre Aquisições em Segurança e Defesa: Impactos na Logística de Defesa
}

\section{The European Directive on Acquisitions in Security and Defence: Impacts on Military Logistics}

\author{
DOI: $10.21530 /$ ci.v12n2.2017.672
}

\author{
Bruna Rohr Reisdoerfer ${ }^{1}$ \\ Luiz Rogério Franco Goldoni²
}

\section{Resumo}

A cadeia de suprimento da logística de defesa tende a ser alvo de forte protecionismo estatal e não faz parte da jurisdição de tratados internacionais. Entretanto, a União Europeia possui uma política única de aquisição em assuntos de segurança e defesa. Ela tem como objetivo, através da diminuição do protecionismo, facilitar o desenvolvimento de um mercado de equipamentos de defesa que iria reduzir a duplicação, aumentar a competição industrial e assim diminuir os preços dos equipamentos dentro do bloco. Todavia, na prática, ocorre a duplicação das capacidades estratégicas dos países. A hipótese do trabalho é que a Diretiva Única 2009/81/EC, relativa a aquisições em segurança e defesa é uma resposta dos países do bloco europeu às pressões de autoajuda do sistema internacional advindas da configuração securitária do pós Guerra Fria. Ela é, portanto, reativa e não ativa às dinâmicas internacionais e é utilizada como instrumento estatal. Todavia, essa característica acaba levando a Diretiva a uma eficiência secundária, pois os países europeus buscam mecanismos para escapar da livre concorrência imposta por ela e para manter certa proteção à capacidade nacional de produção de armamentos sensíveis. O presente trabalho pretende verificar como se estrutura essa política de aquisições na União Europeia - bem como demonstrar os antecedentes que permitiram o seu desenvolvimento.

Palavras-chave: Segurança e Defesa; Logística de Defesa; Política de Aquisição; União Europeia; Diretiva Única 2009/81/EC

1 Escola de Comando e Estado-Maior do Exército. Rio de Janeiro/RJ, Brasil. E-mail: brunareisdoerfer@gmail.com

2 Escola de Comando e Estado-Maior do Exército. Rio de Janeiro/RJ, Brasil.

Artigo submetido em 15/05/2017 e aprovado em 24/08/2017. 


\begin{abstract}
The supply chain of military logistics is usually heavily protected by the state and is not part of the jurisdiction of international treaties. However, European Union has a single defence procurement policy. It aims, through the reduction of protectionism, to facilitate the development of a defence equipment market that reduces duplication, increase industrial competition and thus decreases the prices of equipment within the bloc. However, in practice, there has been a doubling of countries' strategic capabilities. The working hypothesis is that EU Defence and Security Procurement Directive 2009/81/EC is an answer of the European bloc countries to the self-help pressures of the International System stemming from the post-Cold War security configuration. It is therefore, reactive and not active to international dynamics and is used as a state instrument. However, this characteristic leads the Directive to a secondary efficiency, since the European countries seek mechanisms to escape the free competition imposed by it and to maintain some protection to the national capacity to produce sensitive weapons. The objective of the work is to verify how this defence procurement policy is structured in the European Union, as well as, to demonstrate the antecedents that allowed its development.
\end{abstract}

Keywords: Defence and Security; Military Logistics; Defence Procurement; European Union; Directive 2009/81/EC

\title{
Introdução
}

A logística de defesa é um dos componentes da "grande estratégia”3 nacional e auxilia o Estado a alcançar seus objetivos em tempos de paz e de guerra através do suporte ao deslocamento, manutenção, mobilização e posicionamento de suprimentos, tropas e equipamentos (SILVIA; MUSETI, 2003). De forma específica, a política de aquisição de armamentos, sistemas e serviços de segurança e defesa é prerrogativa estatal e se configura como um dos pilares essenciais da cadeia de suprimento de um país (RUSSEL, 2011). É ela que vai determinar quais aquisições devem ser feitas, qual a melhor forma de fazê-las e com quem se deve comercializar a fim de alcançar os melhores benefícios para a segurança e defesa nacionais. Ademais, a política de aquisições determina o equilíbrio entre a importação de produtos ou a compra interna deles. Por isso, ela está também

3 Segundo Silva (1981, p. 25), grande estratégia ou estratégia geral é “arte da competência exclusiva do governo que coordena, dentro de um Conceito Estratégico Fundamental, todas as atividades políticas, econômicas, psicossociais e militares que visam concorrentemente à consecução dos objetivos nos quais se consubstanciam as aspirações nacionais de unidade, de segurança e de prosperidade crescente”. 
diretamente interligada à política de fomento à base industrial de defesa de uma nação (MARKOWNSKI; HALL; WYLIE, 2010). Por ser tão importante para a soberania nacional, a cadeia de suprimento da logística de defesa - especificamente a política da base industrial de defesa e a de aquisições - tende a ser alvo de forte protecionismo estatal e não faz parte da jurisdição de tratados internacionais (MARKOWNSKI; HALL; WYLIE, 2010).

Todavia, a União Europeia possui uma política única de aquisição em assuntos de segurança e defesa que está incorporada nas leis dos países membros (TRYBUS, 2014). Essa política está consubstanciada na Diretiva Única 2009/81/EC da União Europeia (UNIÃO EUROPEIA, 2009). As diretivas são instrumentos jurídicos, pelos quais as políticas da União Europeia são aplicadas nos Estados membros. Para que elas tenham efeito no âmbito nacional, os países têm de transpô-las para o seu direito nacional. Portanto, pode-se dizer que as diretivas estabelecem uma política comum a ser seguida pelos países, mas deixam margem para que os Estados elaborem legislação própria para determinar como as regras serão aplicadas. As diretivas têm prazos máximos para serem transpostas nacionalmente. Tais prazos são determinados quando da adoção da diretiva pela União Europeia. Os países que não cumprirem o prazo estipulado para transposição sofrem processos de infração junto ao Tribunal de Justiça da União Europeia (EUROPEAN UNION, 2015).

A Diretiva Única 2009/81/EC (UNIÃO EUROPEIA, 2009) faz parte do chamado Pacote de Defesa da União Europeia, implementado em 2009, mas que tem origem (como será demonstrado) no fim dos anos 1990 com os movimentos em prol de regulamentação comum entre os países europeus em matéria de armamentos. O supracitado pacote engloba - além da diretiva objeto deste estudo - um comunicado da Comissão Europeia (intitulado "Estratégia para uma indústria de defesa europeia mais forte e competitiva") e outra diretiva referente à transferência de produtos de defesa dentro do bloco (a Diretiva/2009/43/EC) (EUROPEAN PARLIAMENT, 2015, p. 8).

Na teoria, o objetivo da política de aquisição comum é, através da diminuição do protecionismo dentro do bloco, facilitar o desenvolvimento de um mercado de equipamentos de defesa que iria evitar a duplicação, aumentar a competição industrial e assim reduzir os preços dos equipamentos dentro do bloco (EDWARDS, 2011). Ela é uma tentativa de manter a competitividade do mercado de armamentos europeu frente à pressão por diminuição nos orçamentos de defesa do bloco no pós Guerra Fria (JONES, 2007) e, principalmente, frente ao protagonismo de Estados Unidos e Rússia e a crescente presença da China no mercado internacional de armamentos convencionais (SIPRI, 2017). No início da presente década, pela 
primeira vez, a China apareceu como um dos cinco principais exportadores de material bélico, desbancando posição ocupada tradicionalmente pelo Reino Unido (HOLTON et al., 2013; GOLDONI; DOMINGOS NETO, 2014).

No ano de 2016, Estados Unidos e Rússia juntos representavam mais de $50 \%$ do mercado de exportações de armamentos convencionais. França (quarto lugar no ranking global, com 6\%), Alemanha (quinto lugar, com 5,6\%) e Reino Unido (sexto lugar, com 4,6\%) juntos foram responsáveis por um pouco mais de $16 \%$ das exportações de material bélico no mundo. Destaca-se que, entre 2007 e 2016, a China (terceira colocada no ranking de 2016) aumentou sua participação nesse mercado de 3,8\% para 6,2\% (FLEURANT et al., 2017) ${ }^{4}$.

O presente estudo, ao focar sobre a dinâmica dos países europeus na busca pela manutenção da competitividade no mercado global de armamentos, mostrase importante para a realidade brasileira em vista das parcerias estratégicas com França (construção do submarino nuclear brasileiro e de satélite de observação), Suécia (construção do caça de combate Gripen) e Alemanha (compra de carros de combate Leopard).

Nesse contexto, questiona-se quais foram os fatores que influenciaram os Estados europeus a buscarem uma política de aquisições em segurança e defesa comum na União Europeia. Parte-se da hipótese de que a Diretiva Única 2009/81/ EC (UNIÃO EUROPEIA, 2009), relativa a aquisições em segurança e defesa, é uma resposta dos países do bloco europeu às pressões de autoajuda do sistema internacional advindas da configuração securitária do pós Guerra Fria. Ela seria, portanto, reativa e não ativa às dinâmicas internacionais e seria utilizada como instrumento estatal. Todavia, essa característica acaba levando a Diretiva a uma eficiência secundária, pois os países europeus buscam mecanismos para se proteger da livre concorrência imposta por ela e para manter certa proteção à capacidade nacional de produção de armamentos sensíveis.

O presente trabalho tem como objetivo desenvolver um esforço analítico acerca da Diretiva Única 2009/81/EC (UNIÃO EUROPEIA, 2009), a fim de verificar quais são seus antecedentes e como ela se estrutura. Conjuntamente à revisão bibliográfica de literatura especializada, faz-se uma análise de conteúdo implícito e explícito (BARDIN, 2002; CAVALCANTE; CALIXTO; PINHEIRO, 2014) da jurisdição europeia referente à diretiva em questão e se emprega o rastreamento de processo (VENESSON;

4 Top 10 de países exportadores de armamentos do mundo entre 2012-2016 por porcentagem da parcela global (em ordem decrescente): Estados Unidos (33\%), Rússia (23\%), China (6,2\%), França (6\%), Alemanha (5,6\%), Reino Unido (4,6\%), Espanha (2,8\%), Itália (2,7\%), Ucrânia (2,6\%) e Israel (2,3\%) (FLEURANT et al., 2017). Para série histórica detalhada, ver GRAF. 1 e 2 do presente artigo. 
WIESNER, 2014) para auxiliar a prospectar os antecedentes que levaram os países a desenvolverem a legislação conjunta em área tão sensível ao estado-nação.

Cabe, inicialmente, diferenciar a Diretiva Única Europeia 2009/81/EC (UNIÃO EUROPEIA, 2009) das regulamentações da Organização do Tratado do Atlântico Norte (OTAN). A OTAN possui diversas agências subsidiárias que dão suporte para as aquisições no setor de defesa, por exemplo, a Agência de Suporte da OTAN. Ela é a agência que provê serviços e logística integrada e tem como missão prover suporte coletivo e individual aos Estados membros da aliança (TRYBUS, 2014). Esses organismos da OTAN não visam regular as aquisições de defesa dos Estados membros como a Diretiva da União Europeia faz, pois não possuem legislação vinculante a ser transposta para a lei nacional. Isto é, não é obrigatório que um país utilize os regulamentos das agências da OTAN para a aquisição de serviços ou produtos de defesa. Ela é somente um mecanismo de auxílio disponível aos países membros que assim desejarem. Uma das funções da agência é efetuar contratos públicos individuais ou em grupos como parcerias de apoio (TRYBUS, 2014).

Ademais, convém explicitar que o processo de saída do Reino Unido do bloco europeu - chamado de BREXIT - produz incertezas quanto ao futuro das instituições europeias, sendo difícil prever as consequências desse movimento na Diretiva 2009/81/EC (UNIÃO EUROPEIA, 2009). Destaca-se que o presente trabalho não objetiva prospectar os impactos do BREXIT na Diretiva Única. Tal tema pode ser assunto de uma nova agenda de pesquisa assim que houver maiores dados sobre o processo de negociação entre a União Europeia e o Reino Unido. Entretanto, uma nota informativa da Câmara dos Comuns declara que a saída do Reino Unido da União Europeia pode ter pouco impacto na cooperação em defesa do continente no que tange à logística de defesa (ALLISON, 2016).

A saída da UE não irá proibir o RU de trabalhar de perto com as nações europeias individuais para aquisição conjunta de equipamentos, exercícios ou desenvolvimento conjunto de operações militares. As negociações da saída irão decidir se as duas diretivas de defesa da UE serão mantidas. Estas diretivas são desenhadas para fazer com que o mercado interno de defesa europeu trabalhe melhor e para aumentar a competição no setor europeu de defesa. A maioria das companhias de defesa do RU argumentavam, antes do voto favorável, pela manutenção. (HOUSE OF COMMONS, 2016 apud ALLISON, 2016, tradução nossa) ${ }^{5}$

5 Do original em inglês: "Exit from the EU will not prohibit the UK from working closely with individual European nations to jointly procure equipment, exercise or deploy together on military operations. Withdrawal negotiations will decide whether the substance of two EU defence directives are retained. These directives are designed to make 
O presente artigo é separado em cinco seções (além desta introdução). Na primeira, é feita uma breve discussão teórica em torno da cooperação em defesa. Em seguida, são investigados os precedentes que impulsionaram o desenvolvimento de uma diretiva única de aquisições de material de defesa na União Europeia. A terceira seção analisa a Diretiva Europeia Relativa a Aquisições em Segurança e Defesa (Diretiva Única 2009/81/EC (UNIÃO EUROPEIA, 2009)), especialmente seu escopo, objetivos e diretrizes. A quarta seção aborda o desenvolvimento do avião de transporte A400M Atlas, projeto europeu que pode produzir efeito positivo na busca por uma maior cooperação em logística de defesa. Por fim, as considerações finais apresentam reflexões sobre o impacto da Diretiva na cooperação em segurança e defesa do bloco europeu.

\section{Cooperação em defesa: breve análise teórica das relações internacionais}

A cooperação nas relações interestatais é tema de acalorado debate entre diversas correntes teóricas, tanto na literatura específica acerca da cooperação europeia - chamada de estudos europeus - quanto na de teoria das relações internacionais (ROSAMOND, 2000). Uma análise pormenorizada desses debates foge do escopo e fôlego do presente artigo. Cabe aqui, de forma breve, apontar as diretrizes teóricas seguidas pelo trabalho. Adota-se a visão do realismo neoclássico acerca da cooperação em defesa na União Europeia.

As premissas básicas da escola realista das relações internacionais defendem que a política internacional é baseada nas relações de poder, isto é, em relações materiais (DYSON, 2010) (e não em relações subjetivas como identidade, cultura e construções sociais, como defendem os construtivistas (WENDT, 1992)). A ausência de autoridade central (em outras palavras, a anarquia do sistema internacional) faz com que os países só possam contar com suas próprias forças para garantir sua sobrevivência, o que comumente se denomina como sistema de autoajuda (WALTZ, 2000). Isso os leva constantemente a se preocuparem com as ameaças advindas do sistema internacional. Como a anarquia condiciona o mecanismo de autoajuda, os Estados são compelidos a dar atenção em como o poder está distribuído entre eles. O cálculo do poder relativo de um país frente aos demais atores do sistema representa, em última instância, sua capacidade de sobrevivência (MENDES, 2013). 
A busca pela manutenção ou revisão desse poder relativo remete à análise sobre o equilíbrio de poder e a imagem da balança de poder, temas amplamente discutidos em Morgenthau (2003). Todavia, acrescenta-se aqui a ideia de Walt (1987) sobre a balança de ameaças, segundo a qual os Estados não temem de forma igual todos os países e, sim, os que representam as maiores ameaças. Segundo Walt (1987), a intensidade das ameaças securitárias varia de região para região conforme a exposição dos países à estratégia e interesses dos Estados centrais. Essa dinâmica, de acordo com Dyson (2010), leva à convergência de interesses, conduzindo a padrões específicos de cooperação regional. Dessa forma, os Estados podem fazer alianças com países mais fortes a fim de ganhos oportunistas (DYSON, 2010).

$\mathrm{Na}$ lógica do Estado como ator principal, a escola realista defende que as instituições de cooperação em segurança e defesa servem como um mecanismo dos Estados para alcançar seus objetivos nacionais (MEARSHEIMER, 1995), pois são eles quem as criam, moldam e escolhem quando obedecê-las (WALTZ, 2000). Ainda conforme Waltz (2000), as instituições internacionais e a cooperação seriam instrumentos empregados pelos países para garantir sua sobrevivência no sistema de autoajuda. A utilização desses mecanismos e a busca por uma maior cooperação entre os Estados seriam impulsionadas pelo término da Guerra Fria. A estrutura bipolar possibilitava uma dinâmica em que as políticas das potências centrais tinham preponderância frente a outras iniciativas de cooperação, inclusive regionais. Como qualquer ganho de poder por um lado representaria uma perda de poder para o outro, a manutenção do equilíbrio de poder fazia com que as superpotências se comprometessem com a defesa e securitização de suas zonas de influência (WALTZ, 2000). Portanto, segundo essa ótica, as instituições não teriam poder de mudar a ação estatal, como defende a corrente teórica neoliberal das relações internacionais (KEOHANE; NYE, 2011) ${ }^{6}$.

Essas premissas poderão ser percebidas mediante análise dos condicionantes da Diretiva Única 2009/81/EC da União Europeia (UNIÃO EUROPEIA, 2009) e de sua estrutura. Pois, como será explicitado, ela não molda a ação estatal e, sim, serve de instrumento do Estado quando lhe é conveniente. Jones (2007) estuda o comportamento das empresas de defesa europeias durante e após a Guerra Fria. No decorrer daquele período, os países europeus cooperavam mais com os Estados Unidos e suas empresas de armamentos; quase não havia cooperação entre os países e as empresas europeias. Com a quebra da ordem bipolar, Alemanha,

6 Conforme Mearsheimer (1995), o neoliberalismo só teria validade para explicar a influência das instituições em situações nas quais os Estados não têm nada a perder. 
França e Reino Unido passariam a empreender esforços para o desenvolvimento e a produção conjunta de armamentos; bem como a realizar fusões e aquisições. As potências europeias objetivavam diminuir a dependência frente aos Estados Unidos e aumentar a capacidade de projetar poder autonomamente (JONES, 2007). Todavia, tais esforços somente surtiriam efeitos no século XXI.

A guerra no golfo Pérsico, em 1991, a Guerra na Bósnia, em 1995, e a do Kosovo, em 1999, evidenciaram que as potencias europeias continuavam dependentes dos Estados Unidos para desenvolver e sustentar operações militares (HOWORTH, 2007). Um relatório da Comissão Europeia de 1997 concluiu que havia um risco de que a indústria de defesa daquele continente pudesse ser reduzida a exercer o papel de subfornecedora em contratos principais com os Estados Unidos, ficando a tecnologia principal reservada para as empresas americanas (EUROPEAN COMMISSION, 1997).

O poder americano criou uma profunda preocupação entre os governos europeus e líderes industriais de que uma falha em colaborar através de fusões e aquisições, coprodução e codesenvolvimento de projetos pode colocá-los em perigo de dependência dos Estados Unidos de plataformas e armas. (JONES, 2007, p. 180, tradução nossa) ${ }^{7}$

Dentro da escola realista de relações internacionais, pode-se perceber ao menos três vertentes: realismo clássico, realismo estrutural e realismo neoclássico (RYNNING, 2011). O realismo clássico entende que o foco está na agência e não na estrutura. Isto é, são as características internas de cada país (história, escolhas políticas dos líderes etc.) que explicam as ações estatais (RYNNING, 2011). Já o realismo estrutural trabalha com a ideia de que é somente a estrutura do sistema internacional - sem intervenção de variáveis no nível da agência - que produz os principais incentivos às ações estatais (WALTZ, 2002). Já o realismo neoclássico entende que as ações estatais são condicionadas pela estrutura internacional, mas as variáveis internas agem como intervenientes, determinando o tempo e a forma de reposta dos Estados à balança de ameaças do sistema internacional (DYSON, 2010).

Portanto, segundo Dyson (2010), é o sistema internacional (especialmente a balança de ameaças e a anarquia) que pressiona a ação estatal a agir de forma

7 Do original em inglês: "US power created deep concern among European government and industry leaders that a failure to collaborate through M\&As, coproduction projects, and codevelopment projects might place them in danger of dependence on the US for weapons and platforms” (JONES, 2007, p. 180). 
racional e com ambição pelo poder; o ator que não agir assim será punido com declínio, derrota ou mesmo destruição. Portanto, a lógica da anarquia internacional dirige a mudança no nível doméstico de forma que o Estado produza as reformas necessárias para se conformar com os novos desafios securitários. Assim, haveria três opções de ação para os Estados frente a uma mudança na natureza das ameaças no sistema internacional: 1) continuação das práticas já existentes essa opção irá punir os Estados com estagnação, perda de influência e poder; 2) emulação da melhor prática, isto é, imitação das inovações militares do Estado com capacidade mais efetiva; 3) inovação: invenção de novas práticas (DYSON, 2010). Conforme o mesmo autor (2010), a propensão do Estado para emular ou inovar depende da relação de três fatores: recursos tecnológicos, intensidade da competição/ameaças (se a ameaça for mais intensa, os Estados irão preferir emular devido à certeza que ela traz, pois a inovação traz riscos de não dar certo) e opção de alianças (que pode incentivar a se alinhar ao polo para tirar proveito das inovações dos países).

Portanto, de acordo com o realismo neoclássico de Dyson (2010), a cooperação em defesa na União Europeia seria a forma que os Estados europeus escolheram para emular parcialmente as inovações militares americanas. Assim, como será analisado na seção seguinte, a Diretiva Única 2009/81/EC relativa a aquisições em segurança e defesa (UNIÃO EUROPEIA, 2009) seria uma resposta dos países do bloco europeu às pressões de autoajuda do sistema internacional advindas da configuração securitária do pós Guerra Fria.

\section{Precedentes da Diretiva Única de Aquisição da União Europeia}

No imediato pós Segunda Guerra Mundial, os países da Europa ocidental contavam com a cooperação com os Estados Unidos para reconstruir suas indústrias de defesa e se rearmarem ${ }^{8}$. Essa parceria se dava através de licenças e transferência de tecnologia (EDWARDS, 2011). Foi somente nos anos de 1960, quando os europeus já haviam se restabelecido, que a cooperação intrabloco se iniciou como forma de competir com as empresas americanas no mercado

8 Tal prática remete ao Lend-Lease Act ou Bill aprovado pelo congresso estadunidense em março de 1941. “Através deste instrumento jurídico, o Presidente dos Estados Unidos podia, discricionariamente, vender, arrendar, emprestar ou trocar armas ou outros equipamentos para defesa com qualquer país, 'cuja defesa o Presidente julgasse vital para a defesa dos Estados Unidos” (ALVES, 2002, p. 117). 
de armamentos. Tal cooperação se manteve em níveis triviais, pois era elevado o protecionismo entre os países (EDWARDS, 2011). O fim da Guerra Fria levou a um corte nos orçamentos de defesa (LESKE, 2013). Essa tendência passou a ser invertida com a emergência das chamadas "novas ameaças" (SALES, 2016). Somente após 2001 há retomada do crescimento dos investimentos em defesa, provavelmente por influência do 11 de setembro (SALES, 2016; SIPRI, 2016; YANG et al., 2015).

O perigo de um Estado territorial nuclear expansionista deu espaço a ameaças híbridas e irregulares fora das fronteiras nacionais (como terrorismo, armas de destruição em massa etc.). Isso, aliado à complexidade e vulnerabilidade da logística para operações além-teatro ${ }^{9}$ e à pressão dos Estados Unidos por maior divisão de custos na OTAN, levou à necessidade de cooperação por parte dos países europeus para manter a capacidade combativa com menores custos (KISTERSKY, 1996; JONES, 2007; KING, 2011).

Após a dissolução da União Soviética, os Estados Unidos chegaram a ser responsáveis por quase $60 \%$ do mercado de exportação de armamentos convencionais (o ápice do domínio mercadológico estadunidense ocorreu em 1992, conforme pode ser observado nos GRAF. 1 e 2) (SIPRI, 2017). O medo do monopólio e de que as empresas europeias fossem reduzidas a um papel secundário ou subsidiário, aliado à incerteza da proteção americana caso necessário, pressionou os países europeus a cooperarem através de projetos conjuntos, fusões e aquisições (JONES, 2007). Somente a partir de 1999 os norte-americanos teriam seu predomínio reduzido nas exportações globais de armas convencionais (conforme pode ser observado no GRAF. 1), devido, principalmente, à recuperação dos investimentos russos. Na série histórica analisada (1989-2016), chama também atenção o encolhimento das exportações britânicas e o crescimento chinês, que dobrou sua porcentagem nas exportações globais de armamentos convencionais (ver GRAF. 2) ${ }^{10}$.

9 Operações além-teatro dizem respeito às operações fora do território previsto para que a força militar desenvolva as suas funções (HURA et al., 2000).

10 Foram elaborados dois gráficos para a representação temporal (um para a representação de Estados Unidos e URSS/Rússia e outro para representação de Alemanha, França, Reino Unido e China) a fim de facilitar a visualização devido aos altos valores de Estados Unidos e URSS/Rússia. A base de dados sobre transferência de armamentos do SIPRI não visa disponibilizar o valor financeiro internacional do comércio de armas, mas sim indicar o volume de equipamentos militares transferidos no mundo (FLEURANT et al., 2017). 
Gráfico 1 - Variação percentual na participação dos Estados Unidos e União Soviética (URSS)/Rússia no mercado global de exportação das principais armas convencionais entre 1989-2016

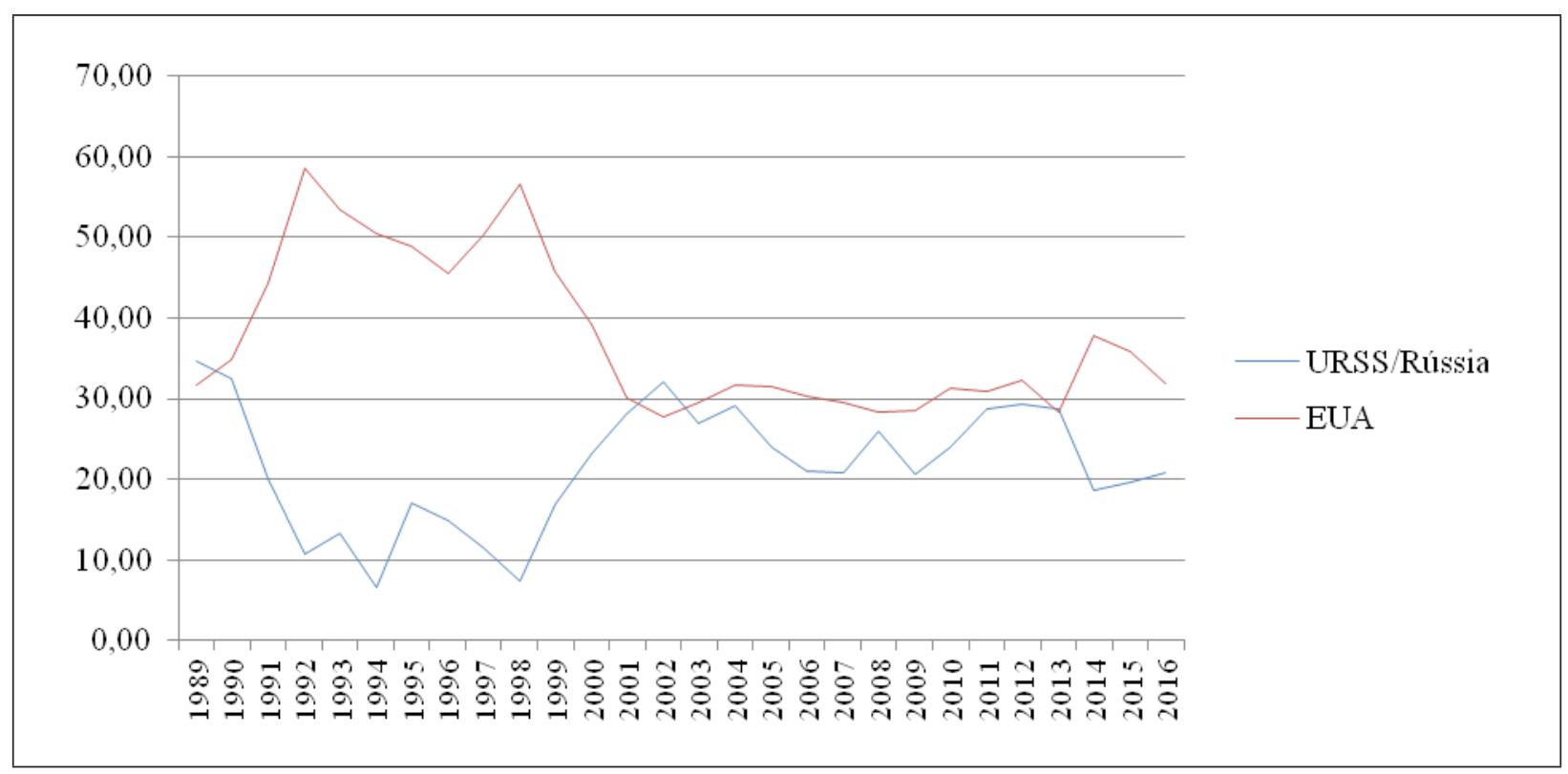

Fonte: elaboração própria com base nos dados de SIPRI, 1989-2016.

Gráfico 2 - Variação percentual na participação de Reino Unido, França, Alemanha Ocidental/República Federal da Alemanha e China no mercado global de exportação das principais armas convencionais entre 1989-2016

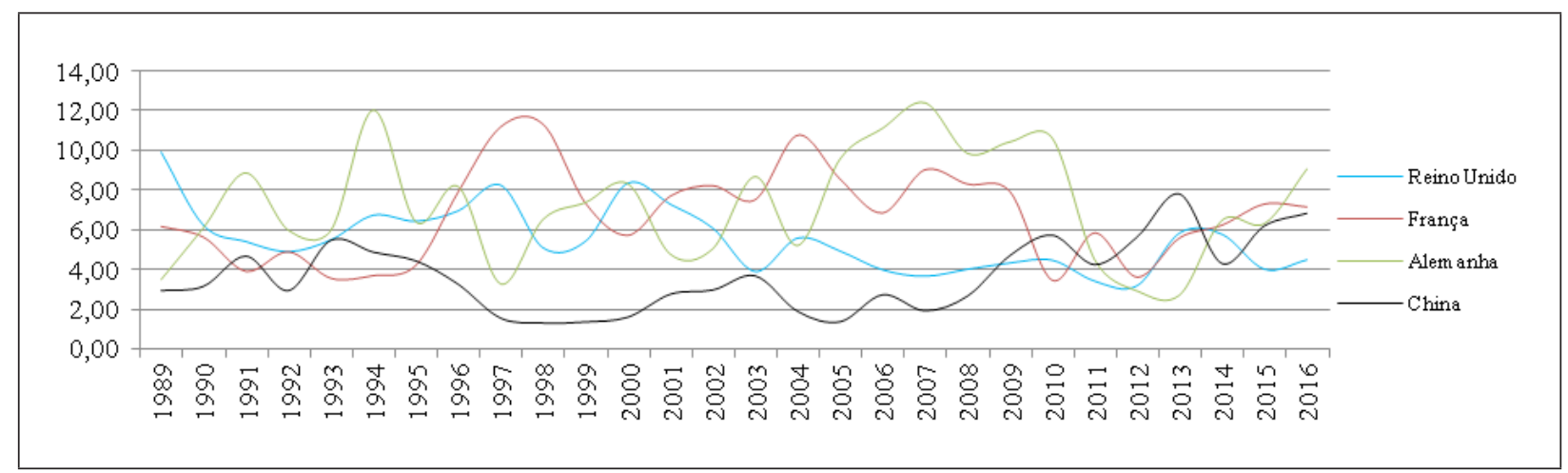

Fonte: elaboração própria com base nos dados de SIPRI, 1989-2016.

Com o fim da Guerra Fria e a diminuição do orçamento de defesa, os Estados Unidos adotaram a estratégia das campeãs nacionais para dominar o mercado internacional. Isto é, houve fusões e aquisições para melhorar a eficiência das empresas americanas (JONES, 2007). Nos anos de 1990, Lockheed Martin e Boeing eram as empresas de armamentos dominantes no mundo (JONES, 2007). Isso impactou diretamente a Europa, que via esse crescimento como uma possível ameaça: 
A indústria de defesa europeia está muito fragmentada para ser sustentável. A queda acentuada da demanda após o fim da Guerra Fria, combinada com a feroz concorrência de corporações "gigantes” recém-criadas nos Estados Unidos colocou em risco o futuro desta indústria. (EUROPEAN COMISSION, 1997, tradução nossa) ${ }^{11}$

Como resposta a essa nova arquitetura de segurança do pós Guerra Fria, houve, nos anos de 1990, o aumento da cooperação política europeia. Cabe ressaltar a assinatura do Tratado de Maastricht, em 1992. Ele institucionalizou as iniciativas que vinham sendo feitas na cooperação em segurança e defesa. O tratado criou uma Política Externa e de Segurança Comum do bloco (PESC) (COUNCIL OF THE EUROPEAN COMMUNITIES, 1992). Em junho do mesmo ano, foi feita a Declaração de Petersburgo que definiu que a União Europeia poderia acionar a União da Europa Ocidental para desenvolver operações militares em missões humanitárias de salvamento, missões de manutenção da paz, gestão de crises e pacificação (EUROPEAN FOREIGN POLICY UNIT, 2012).

Em 1996, houve o estabelecimento da Organização para Cooperação Conjunta em Matéria de Defesa (OCCAR - sigla em francês) entre França, Alemanha, Itália e Reino Unido (JONES, 2007). Ela estabeleceu o princípio do “retorno justo”. Esse princípio determinou que a indústria de defesa de cada país deveria receber um retorno de no mínimo $66 \%$ do valor que o governo daquele país investisse no programa conjunto. O princípio foi positivo no sentido de incentivo à divisão de custos entre os Estados membros, fomentando projetos que seriam muito custosos para um país sozinho realizar; mas resultou em ineficiência, pois cada nação ficava responsável por desenvolver e produzir certas partes de determinado programa conjunto. Recentemente, a OCCAR substituiu o sistema do retorno justo - com base em análises de cada programa - por um no qual há uma revisão anual da divisão de trabalho, o que torna as parcerias mais produtivas e duradouras (EDWARDS, 2011).

Em 1997, a Comissão Europeia produziu um documento sobre o setor de defesa europeu, conhecido como Relatório Bangemann (GREVI; KEOHANE, 2009). Esse relatório previa propostas para a criação de um mercado comum de armamentos (incluindo um sistema de licença para transferência de produtos de defesa internamente), a promoção de procedimentos de licitação pública

11 Do original em inglês: "The european defence-related industry is too fragmented to be sustainable. The sharp drop in demand following the end of the cold war, combined with fierce competition from newly created 'giant' corporations in the United States has put the future of this industry at stake” (EUROPEAN COMISSION, 1997). 
para aquisição de equipamentos de defesa e a eliminação de direitos aduaneiros sobre alguns produtos de defesa. Outras medidas sugeridas no relatório incluíam a alteração das regras de concorrência do bloco (para permitir que a Comissão Europeia fiscalizasse o comércio de todos os tipos de equipamento de defesa), padronização dos procedimentos de aquisição e o estabelecimento de competências claras para o uso dual pela Comissão Europeia (EUROPEAN COMMISSION, 1997).

No ano seguinte, França, Alemanha, Reino Unido, Suécia, Espanha e Itália assinaram uma Carta de Intenção (Letter of Intention - LoI) em que concordavam que os países deveriam harmonizar a operabilidade de seus armamentos a fim de diminuir a duplicação de capacidades e continuarem competitivos no sistema internacional (JONES, 2007). A LoI versava especificamente sobre a logística de defesa dentro do bloco europeu (EDWARDS, 2011) e serviu como um dos precedentes da atual Diretiva Europeia 2009/81/EC relativa a aquisições em segurança e defesa. Ela possuía sete princípios. Desses, conforme Edwards (2011), os mais relevantes são:

1) Segurança de abastecimento: o suprimento de armamentos e serviços de defesa deve ser mantido em tempos de paz e de guerra;

2) Exportação: a reestruturação da base industrial de defesa europeia não poderia trazer impeditivos à exportação de produtos e serviços de defesa dos países membros;

3) Segurança da informação: a segurança da informação deveria ser garantida sem impor restrições desnecessárias ao movimento de staffs, informações e material entre os países.

Em grande parte, como resposta à dependência de capacidades americanas para a realização das operações nos Balcãs, no ano 2000, a carta se transformou em um acordo. Após o desenvolvimento da primeira força militar com bandeira da União Europeia, em 2003 (MISSIROLI, 2003), ocorreu a criação da Agência Europeia de Armamento, em 2004. Ela tinha cinco funções relacionadas à busca por uma cadeia de suprimento europeia: desenvolver capacidades de defesa, promover pesquisa e tecnologia de defesa, fortalecer a base industrial e tecnológica de defesa, promover a cooperação em armamentos e criar um mercado competitivo europeu de equipamentos de defesa.

Em 2006, a agência lançou um código de conduta para aquisições em segurança e defesa (exceto para pesquisa e desenvolvimento), servindo de precedente para 
a Diretiva Única 2009/81/EC (UNIÃO EUROPEIA, 2009). O código previa que os países membros deveriam abrir para competição dos outros países membros todos os contratos acima de um milhão de euros enquadrados como itens não essenciais à defesa nacional ${ }^{12}$. Isso seria feito através de um sítio eletrônico que divulgaria os contratos em busca de possíveis fornecedores. Até 2011, 385 contratos haviam sido postos sob competição - um terço desses foi transfronteiriço (EDWARDS, 2011).

Outro precedente da Diretiva Única 2009/81/EC (UNIÃO EUROPEIA, 2009) que vale ser mencionado é a Diretiva do Setor Público 2004/18/EC (UNIÃO EUROPEIA, 2004). Ela versa sobre as aquisições do setor público em geral, mas não traz especificações sobre aquisições em segurança e defesa e, por isso, quando estava em vigor, não permitia que os Estados membros obtivessem do mercado interno legislação referente às aquisições da logística de defesa. Ela somente fomentava a utilização, pelo bloco, do Artigo $346^{13}$ do Tratado sobre o Funcionamento da União Europeia (TFUE).

\section{A Diretiva Europeia Relativa a Aquisições em Segurança e Defesa}

Visando prover uma legislação específica sobre aquisições em defesa, em 2009, após anos de preparação e discussão (com os esforços da OCCAR, da Agência de Defesa Europeia, da Comissão Europeia, da Carta de Intenção e sua posterior transformação em acordo), a Diretiva Única em Aquisições de Segurança e Defesa 2009/81/EC entrou em vigor juntamente com a Diretiva 2009/43/EC sobre transferência dentro da união de materiais de defesa e a declaração da Comissão Europeia sobre a "Estratégia para uma indústria de defesa europeia mais forte e competitiva" - chamados de Pacote de Defesa 2009 (EUROPEAN PARLIAMENT, 2015, p. 8). A Diretiva Única 2009/81/EC foi aprovada no Conselho da União Europeia em 2009 com 26 países a favor ${ }^{14}$, representando uma resposta (pelo menos dentro das instituições) às pressões sistêmicas de redução nos gastos de

\footnotetext{
12 Segundo a legislação da Diretiva Única 2009/81/EC, quatro tipos de armamentos podem ser enquadrados como sensíveis: armamentos e poder nuclear, sistema de armas complexo, sistemas de comunicação complexa, de detecção e sistemas furtivos (EDWARDS, 2011).

13 Conforme Edwards (2011, p. 8), o artigo 346 determina que: 1) as provisões da Diretiva não devem ser aplicadas quando o Estado membro considera a divulgação de informações contrárias aos interesses da segurança e defesa nacional; 2) qualquer Estado pode tomar as medidas necessárias para a proteção dos interesses essenciais da sua segurança que estejam ligadas com a produção ou comércio de armamentos militares.

14 Somente a Polônia se absteve; Croácia entraria no bloco apenas em 2013.
} 
defesa, aumento da fatia de mercado dos Estados Unidos e incerteza de possível auxílio americano em caso de necessidade (TRYBUS, 2014). Dessa forma, pode-se dizer que a Diretiva de Defesa resultou da adaptação da Diretiva do Setor Público 2004/18/EC, trazendo para dentro das instituições do bloco questões centrais para a logística de defesa, que vinham sendo discutidas dentro dos órgãos específicos (OCCAR e Agência Europeia de Armamentos) como a segurança de suprimento e da informação (TRYBUS, 2014). Conforme Trybus (2014), o objetivo da regulação europeia para aquisição em segurança e defesa é diminuir o protecionismo dentro do bloco a fim de promover uma cadeia de suprimento supranacional para evitar a duplicação de capacidades e o desperdício de recursos. Segundo o mesmo autor (2014), isso promoveria a utilização mais racional dos recursos escassos destinados à defesa para tornar os países europeus mais competitivos no mercado internacional de armamentos. Além disso, esperava-se que houvesse maior transparência nos contratos do setor e uma revisão das legislações nacionais a fim de se estabelecer um mercado interno para produtos e serviços de segurança e defesa (TRYBUS, 2014).

A Diretiva Única 2009/81/EC (UNIÃO EUROPEIA, 2009) regula os procedimentos da aquisição, as situações que ela pode ser utilizada, as condições de contrato, a qualificação dos licitantes, os critérios de seleção de um contratante, as compensações e subcontratos e a legislação para os concorrentes lesados (TRYBUS, $2014)^{15}$. Os atores que nela se enquadram são os governos centrais, regionais ou autoridades locais, corpos governados pela lei pública, associações formadas por uma ou mais dessas autoridades ou por um ou mais desses corpos (UNIÃO EUROPEIA, 2009). A Diretiva é aplicável à aquisição: i) de equipamentos militares e equipamentos sensíveis (incluindo suas partes, componentes e elementos de ligação); ii) obras e serviços diretamente relacionados a esses equipamentos em relação a um ou a todos os elementos de seu ciclo de vida; iii) obras e serviços para fins militares específicos, ou obras e serviços sensíveis. Seu escopo se delimita a contratos com valor estimado (sem o imposto sobre o valor acrescentado) igual ou superior a EUR 412.000 para os contratos de serviços e EUR 5.150.000 para os contratos de aquisição de obras e equipamentos (UNIÃO EUROPEIA, 2009).

Especificamente, os produtos que não entram na jurisdição da Diretiva 2009/81/EC (UNIÃO EUROPEIA, 2009) e que ainda não foram enquadrados nas

15 A literatura especializada em logística mostra que a governança da cadeia de suprimentos é elemento fundamental para a diminuição dos gastos de aquisição e manutenção dos sistemas de armamentos nacionais (RANDALL, 2013; RINDFIEISCH; HEIDE, 1997). 
definições acima são: i) os contratos relacionados a serviços de inteligência; ii) os contratos de pesquisa e desenvolvimento entre pelo menos dois Estados membros do bloco para desenvolvimento de um novo produto e para todo o ciclo de vida desse produto; iii) os contratos firmados com um terceiro país (inclusive para fins civis) quando as forças militares do bloco estão além-teatro e devem cumprir obrigações com operadores econômicos na zona de operações; iv) os contratos de locação ou aquisição de terrenos ou imóveis existentes; v) os serviços de arbitragem, conciliação e serviços financeiros (com exceção dos de seguros); vi) os contratos de trabalho e vii) os contratos entre dois governos para o fornecimento de equipamento militar ou de equipamento sensível ou obras e serviços diretamente ligados a esse equipamento (UNIÃO EUROPEIA, 2009). Percebe-se que não há clareza na definição do escopo da Diretiva e que há inúmeros caminhos para escapar de sua jurisdição.

Além disso, os países europeus podem invocar, na Corte de Justiça Europeia, o Artigo 346 do TFUE para evitar a utilização da Diretiva. Sublinha-se que a Diretiva Única 2009/81/EC (UNIÃO EUROPEIA, 2009) não subverte regras firmadas pelos países do bloco em organizações internacionais das quais façam parte, ou em acordos estabelecidos entre um ou mais Estados membros com um ou mais terceiros países relativos a armamentos e/ou posição de tropas (TRYBUS, 2014). Assim, a Diretiva não é aplicável nessas situações.

Percebe-se que a alternativa de utilização, por parte dos países, do artigo 346 do TFUE, representa uma possibilidade de os Estados escaparem dos objetivos da Diretiva de diminuição do protecionismo dentro do bloco. Os Estados membros da União Europeia se esforçam para demonstrar que as plataformas complexas, como carros blindados de combate, porta-aviões e caças de supremacia aérea, são integradas de tal forma que não podem ser separadas em contratos de diferentes níveis de segurança. Caberia à Comissão Europeia a discussão sobre a abertura de plataformas ou equipamentos não diretamente ligados àquelas três categorias, como veículos blindados de transporte, barcos de patrulha e sistemas de reabastecimento ar-ar (GREVI; KEOHANE, 2009).

A Diretiva Única 2009/81/EC (UNIÃO EUROPEIA, 2009) prevê que as entidades contratantes podem utilizar como padrão o procedimento por negociação com publicação prévia, o que lhes dá flexibilidade para ajustar todos os detalhes do contrato. Além disso, os candidatos à licitação são obrigados a apresentar garantias relativas à segurança das informações e à segurança de abastecimento. A Diretiva prevê também que os contratantes podem abrir as cadeias de suprimento 
para subcontratos de empresas de pequeno e médio porte (geralmente de países majoritariamente importadores de armamentos na União Europeia, como a Grécia). Ela determina também que as leis e decretos nacionais irão prover a legislação de proteção dos direitos das empresas que participem dos processos de licitação (EUROPEAN COMMISSION, 2016).

No que se refere ao investimento em pesquisa e desenvolvimento (P\&D), a Diretiva pretende encontrar um equilíbrio entre contratos desse tipo e a necessidade de abrir os mercados de produção para a criação de uma cadeia única de suprimentos na Europa. Por isso, ela fomenta a cooperação em pesquisa e desenvolvimento conjunto. Ademais, objetivando manter a capacidade de investimento estatal em P\&D, os projetos nacionais ficaram de fora da legislação comum. Entretanto, a Diretiva prevê que nas fases posteriores do ciclo de vida do produto, ${ }^{16}$ aqueles projetos devem ser abertos à competição europeia. Todavia, essa regra pode não gerar os efeitos esperados, uma vez que há a preocupação de que os Estados membros invistam em um projeto de P\&D e que as empresas da sua base nacional de defesa não vençam o contrato de fabricação (EDWARDS, 2011). Os mecanismos de compensações são enquadrados pela Comissão Europeia como uma prática que precisa ser erradicada, pois os procedimentos de aquisição em segurança e defesa deveriam ser abertos à competição, em que o elemento de decisão seja o preço e a qualidade do produto e não o valor das compensações que ele traz. Por isso, a Comissão Europeia determinou que utilizará o mecanismo de análise caso a caso para determinar a utilização do mecanismo de compensação (EDWARDS, 2011). Em março de 2013, todos os países da União Europeia haviam transpassado a Diretiva Única de Defesa 2009/81/EC (UNIÃO EUROPEIA, 2009) para suas legislações nacionais. Entre agosto de 2011 e março de 2013, 872 contratos foram firmados sob a jurisdição única, representando um total de EUR 1,77 bilhões (TRYBUS, 2014). O valor de quase dois anos de Diretiva é um sexto do orçamento destinado somente em 2007 para o setor, por exemplo. Em 2007 (um ano após a criação do código de conduta pela Agência Europeia de Armamento), os países europeus investiram aproximadamente EUR 32 bilhões em processos de aquisição em defesa, desses, EUR 6 bilhões em programas conjuntos (GREVI; KEOHANE, 2009).

Em 2016, a Diretiva 2009/81/EC foi revisada pelos países da União Europeia e não houve alterações em suas normas. Todavia, até aquele ano, somente $22 \%$

16 Aproximadamente, apenas $30 \%$ do investimento realizado em um sistema de armas é gasto na aquisição ou fabricação desse sistema. Os demais $70 \%$ são gastos na manutenção do sistema que tem o ciclo de vida médio em torno de 25-30 anos (GLAS; HOFMANN; EBIG, 2011). 
das aquisições de defesa dos Estados europeus se deu de forma colaborativa e aberta à livre concorrência. Esse fato reafirmou a duplicação de capacidades e a necessidade de o bloco rever as formas de reforçar a utilização da Diretiva 2009/81/EC (UNITED STATES, 2017).

\section{A Diretiva Única 2009/81/EC e o avião de transporte A400M Atlas}

Ainda há muito o que se fazer para reduzir a duplicação das capacidades europeias e melhorar os problemas de orçamento dos países. Todavia, há exemplos de projetos de cooperação que podem produzir efeito positivo na busca por uma maior cooperação em logística de defesa e, assim, manter a capacidade nacional de combate. É o caso do avião de transporte A400M Atlas.

Conforme anteriormente discutido, as operações nos conflitos de dissolução da antiga Iugoslávia demonstraram fragilidade dos europeus em capacidades estratégicas, dependendo de auxílio americano (JONES, 2007). Assim, Bélgica, França, Alemanha, Espanha, Turquia, Luxemburgo e Reino Unido (agrupados na OCCAR) assinaram um memorando em 2001 para a construção do avião de transporte europeu A400M. Eles visavam romper com a dependência do avião de transporte americano Hércules (JONES, 2007). Atualmente, o A400M é utilizado por França e Turquia nas operações no Afeganistão, Síria, Iraque, Mali, República Centro Africana e região do Sahel (AIRBUS, 2016).

A empresa Airbus (consórcio europeu) é a responsável pelo gerenciamento do projeto (AIRFORCE TECHNOLOGY, 2013) ${ }^{17}$. Em vista do incremento da capacidade autônoma europeia, em março de 2008, o primeiro ministro inglês Gordon Brown e o presidente francês Nicolas Sarkozy anunciaram que iriam criar um fundo para auxiliar no desenvolvimento de aeronaves que seriam utilizadas em operações multinacionais a âmbito da OTAN, União Europeia e Organização das Nações Unidas (ONU) (IISS, 2009). Sublinha-se que o projeto do A400M sofreu atrasos devido justamente a problemas com orçamento.

A primeira célula completa foi lançada em 2008 em Sevilha. Essa sofreu os impactos da crise de 2008 que atrasou o seu desenvolvimento e testes (IISS, 2009). Em janeiro de 2009, a EADS (que hoje faz parte do grupo Airbus) adiou os

17 O projeto A400M se insere na mudança estratégica, operacional e tática que ocorre na Europa desde o fim da Guerra Fria. O aumento da capacidade de projeção de poder para operações além-teatro (KING, 2011) também reflete as pressões americanas para divisão de custos na OTAN. 
primeiros pedidos do A400M para 2012. Em novembro de 2010, Alemanha, França, Reino Unido, Espanha, Turquia e Luxemburgo acordaram em destinar EUR 1,5 bilhões para que o programa continuasse. Todavia, devido a cortes nos orçamentos de defesa, Alemanha e Reino Unido diminuíram o número de aeronaves que iriam adquirir. Em 2013, as primeiras aeronaves foram entregues para a França. Todas as demais devem ser entregues até 2025 (AIRFORCE TECHNOLOGY, 2013). Atualmente, há 174 pedidos do avião; 26 foram entregues e estão em operação (AIRBUS, 2016).

O acordo de defesa assinado entre França e Reino Unido em 2010 (enquadrado pela literatura como Entente Frugale) previa o treinamento conjunto e suporte integrado dos aviões de transporte A400M dos dois países. Isso possibilitaria a redução de custos e impulsionaria uma maior cooperação em matéria de manutenção, logística e treinamento (UNITED KINGDOM, 2011). Essa intenção foi reafirmada em 2014 durante o encontro da RAF Brize Norton. Naquela data, ambos os países concordaram em padronizar determinações técnicas para o aumento da efetividade dos programas de intercâmbio para treinamento de pilotos e engenheiros britânicos no A400M antes da entrega da primeira aeronave inglesa (UNITED KINGDOM, 2014).

A característica tática e estratégica do A400M e seu propósito de construir uma capacidade autônoma europeia, bem como a intenção franco-inglesa de desenvolver interoperabilidade entre seus aviões, podem servir como primeiro movimento para a consecução de uma estrutura de desenvolvimento e uso conjunto militar na Europa.

\section{Conclusões}

Da análise dos precedentes e da Diretiva Única de Aquisição em Segurança e Defesa 2009/81/EC da União Europeia, percebe-se que seu desenvolvimento é fruto de uma reação dos países do bloco europeu à balança de ameaças do pós Guerra Fria. Ela é, portanto, reativa e não ativa às dinâmicas internacionais, levando a uma eficiência secundária, pois os países europeus invocam o Artigo 346 do TFUE para escapar da livre concorrência imposta pela Diretiva. Os primeiros passos para a construção de uma cadeia de suprimento logística em defesa supranacional foram dados, todavia, o processo esbarra em interesses securitários nacionais, demonstrando mais uma vez a centralidade do Estado nas ações relativas à 
logística de defesa que são críticas para a soberania estatal (RUSSEL, 2011) e a instrumentalidade da Diretiva pelos governos nacionais.

A amplitude do escopo da Diretiva 2009/81/EC, seus casos de exceção e a alternativa de acionar o Artigo 346 do TFUE em uma análise caso a caso representam mecanismos de fuga dos objetivos da jurisdição do bloco. Isso sem mencionar que a Diretiva não é aplicável quando há regras firmadas pelos países da UE em organizações internacionais das quais façam parte, ou em acordos estabelecidos entre eles com terceiros países (TRYBUS, 2014).

O uso da Diretiva somente para contratos que versam sobre questões não essenciais para os países continua mantendo a capacidade europeia fragmentada e duplicada (exemplo são os programas de veículos de combate blindados da União Europeia), impactando na sua posição no mercado de armamentos e na dependência dos países do bloco com terceiros países (GREVI; KEOHANE, 2009).

O protecionismo estatal ainda pressiona os países europeus a não cooperarem em projetos estratégicos, o que leva à duplicação das capacidades europeias e a uma competição delas no mercado internacional de armamentos (EDWARDS, 2011). A França, por exemplo, optou por não participar do consórcio entre Alemanha, Reino Unido, Itália e Espanha para construção do caça Eurofigther (EUROFIGTHER THYPOON, 2017). Em vez disso, o país continua o investimento em seu caça similar, Rafale. Devido ao princípio liberal de não permitir que os países façam contratos com base em compensações (como o uso de subcontratos locais, transferência de tecnologia etc.) e sim pelo preço e qualidade do produto, prevê-se a perda de capacidade industrial por parte dos países majoritariamente importadores de armamentos (como Finlândia, Grécia, Polônia, Portugal e Espanha) e uma especialização e beneficiamento dos países exportadores do bloco (como Alemanha, França e Reino Unido). Objetivando a diminuição das assimetrias entre os países e a diminuição da duplicação de capacidades, a Agência Europeia de Armamentos e a OCCAR devem fomentar a utilização, pelos países exportadores do bloco, da cadeia de suprimentos europeia, diminuindo a importação por parte desses países de armamentos americanos que incluem compensações indiretas (é o caso de Itália, Suécia, Holanda e Reino Unido) (EDWARDS, 2011).

A análise do supracitado fomento é tema para uma agenda futura de pesquisa; bem como a investigação sobre os impactos da "superposição" de estruturas e políticas multilaterais dentro do bloco europeu (OCCAR, OTAN, Agência Europeia de Armamentos etc.), que nem sempre englobam todos os países. Esse "embaralhamento" de organismos provoca complementaridade, 
incoerência ou duplicação de recursos e esforços institucionais? Por fim, resta o debate acerca da cooperação e da interdependência. Até que ponto a estrutura do sistema internacional e a pressão por autoajuda possibilitam confiança para a cooperação em temática tão sensível ao Estado nacional como o desenvolvimento de sistemas de armas (que envolve, em muitos casos, transferência de tecnologia e compartilhamento de dados sensíveis)?

\section{Referências}

AIRBUS. A400M: Delivery to the point of need. 2016. Disponível em: < https://airbusdefence andspace.com/our-portfolio/military-aircraft/a400m/ > . Acesso em: 30 ago. 2016. AIRFORCE TECHNOLOGY. A400M (Future Large Aircraft) Military Transport Aircraft. 2013. Disponível em: < http://www.airforce-technology.com/projects/fla/ > . Acesso em: 31 ago. 2016.

ALLISON, G. BREXIT: Defence ties 'not affected' say France. 2016. Disponível em: < https://ukdefencejournal.org.uk/brexit-defence-ties-not-affected-say-france/ > . Acesso em: 2 jul. 2016.

ALVES, V. C. História de um Envolvimento Forçado. São Paulo: Loyola, 2002.

BARDIN, L. Análisis de contenido. Madrid: Akal, 2002.

COUNCIL OF THE EUROPEAN COMMUNITIES. Commision of the European Communities. Treaty on European Union. Brussels; Luxembourg: Office for Official Publications of The European Communities, 1992. Disponível em: < http://europa.eu/eu-law/ decision-making/treaties/pdf/treaty_on_european_union/treaty_on_european_union_ en.pdf > . Acesso em: 09 jul. 2015.

CAVALCANTE, R. B.; CALIXTO, P.; PINHEIRO, M. M. K. Análise de Conteúdo: considerações gerais, relações com a pergunta de pesquisa, possibilidades e limitações do método. Inf. \& Soc, João Pessoa, v. 24, n. 1, jan/abr 2014, p.13-18.

DYSON, Tom. Neoclassical Realism and Defence Reform in Post-Cold War Europe. Basingstoke: Palgrave Macmillan, 2010.

EDWARDS, J. The EU Defence and Security Procurement Directive: A Step Towards Affordability? London: Chatham House, 2011. (International Security Programme Paper ISP PP 2011/05).

EUROFIGTHER THYPOON. How Eurofigther Typhoon Operates. 2017. Disponível em: < https://www.eurofighter.com/about-us > . Acesso em: 02 maio 2017.

EUROPEAN COMISSION. A Europe-wide market for defence products is vital if the industry is to survive. 1997. Disponível em: < http://europa.eu/rapid/press-release_IP-97983_en.htm >. Acesso em: 28 abr. 2017. 
EUROPEAN COMISSION. Defence procurement. 2016. Disponível em: < http://ec.europa. eu/growth/single-market/public-procurement/rules-implementation/defence/index_ en.htm > . Acesso em: 05 jun. 2016.

EUROPEAN FOREIGN POLICY UNIT. Chronology: The Evolution of a Common EU Foreign, Security and Defence Policy. Brussels: European Union, 2012. Disponível em: < http://www.lse.ac.uk/internationalRelations/centresandunits/EFPU/EFPUpdfs/ chronologyEUforpolinstitutions.pdf > . Acesso em: 17 ago. 2015.

EUROPEAN PARLIAMENT. The impact of the 'defence package' Directives on European defence. Brussels: European Union, 2015. Disponível em: < http://www.europarl. europa.eu/RegData/etudes/STUD/2015/549044/EXPO_STU(2015)549044_EN.pdf > . Acesso em: 19 jul. 2017.

EUROPEAN UNION. Diretivas da União Europeia. 2015. Disponível em: < http://eur-lex. europa.eu/legal-content/PT/TXT/?uri = LEGISSUM:114527 > . Acesso em: 19 jul. 2017. FLEURANT, A. et al. Trends in International Arms Transfers: 2016. Sipri Fact Sheet, Solna, v. 1, n. 1, fev. 2017, p.1-12. Disponível em: < https://www.sipri.org/sites/default/ files/Trends-in-international-arms-transfers-2016.pdf > . Acesso em: 28 abr. 2017.

GLAS, A.; HOFMANN, E; EBIG, M. Performance-based logistics: a portfolio for contracting military supply. International Journal of Physical Distribution \& Logistics Management, v. 43, n. 2, 2011, p. 97-115.

GOLDONI, L. R. F.; DOMINGOS NETO, M. Perspectivas da cooperação militar entre os BRICS. Tensões Mundiais, v. 10, n. 18, 19, jan./dez. 2014.

GREVI, G.; KEOHANE, D. ESDP resources. In GREVI, G; HELLY, D.; KEOHANE, D. European Security and Defence Policy: the first 10 years (1999-2009). Paris: European Union Institute for Security Studies, 2009. p. 69-114.

HOLTON, P. et al. Trends in International Arms Transfers, 2012. SIPRI Fact Sheet, SIPRI. Stockholm, mar. 2013. Disponível em: < http://www.sipri.org/publications > . Acesso em: 15 nov. 2013.

HOWORTH, Jolyon. Security and Defence Policy in the European Union. Hampshire: Palgrave Macmillan, 2007.

HURA, M. et al. Interoperability: A Continuing Challenge in Coalition Air Operations. Santa Monica: Rand, 2000.

JONES, S. G. The Rise of European Security Cooperation. Cambridge: Cambridge University Press, 2007.

KEOHANE, R. O; NYE, J. S. Power \& Interdependence. 4 ed. Longman. 2011.

KING, A. The Transformation of Europe's Armed Forces: from the Rhine to Afeghanistan. New York: Cambridge University Press, 2011.

KISTERSKY, L. New Dimensions of the International Security System after the Cold War. Stanford: Stanford University, 1996. Disponível em: < http://cisac.fsi.stanford.edu/ publications/new_dimensions_of_the_international_security_system_after_the_cold_ war > . Acesso em: 01 jul. 2015. 
LESKE, A. D. C. Inovação e Políticas da Indústria de Defesa. 2013; 197f. Tese (Doutorado em Economia) - Instituto de Economia da Universidade Federal do Rio de Janeiro, Rio de Janeiro, 2013.

MARKOWNSKI, S.; HALL, P.; WYLIE, R. (Eds.). Defence Procurement and Industry Policy: A small country perspective. London; New York: Routledge, 2010.

MEARSHEIMER, J. J. The False Promise of International Institutions. International Security, Harvard, v. 19, n. 3, 1995, p.5-49. Disponível em: < http://mearsheimer. uchicago.edu/pdfs/A0021.pdf > . Acesso em: 23 set. 2015.

MENDES, F. P. Lakatos, o Realismo Ofensivo e o Programa de Pesquisa Científico do Realismo Estrutural. 2013. 183 f. Tese (Doutorado) - Curso de Relações Internacionais, Instituto de Relações Internacionais, Universidade de São Paulo, São Paulo, 2013. Disponível em: < http://www.iri.usp.br/documentos/defesa_13-02-14_Flavio_ Pedroso_Mendes.pdf > . Acesso em: 14 mar. 2017.

MISSIROLI, A. (Comp.). From Copenhagen to Brussels: European Defence: core documents. 67. ed. Paris: Institute For Security Studies, 2003. Disponível em: < http://www.iss. europa.eu/uploads/media/cp067e.pdf > . Acesso em: 14 set. 2015.

MORGENTHAU, H. J. A política entre as nações: a luta pelo poder e pela paz. Brasília: Editora Universidade de Brasília, Instituto de Pesquisa de Relações Internacionais; São Paulo: Imprensa Oficial do Estado de São Paulo, 2003.

RANDALL, W. S. Are the Performance Based Logistics Prophets Using Science or Alchemy to Create Life-Cycle Affordability? - Using Theory to Predict the Efficacy of Performance Based Logistics. Defense ARJ, v. 20, n. 3, oct. 2013, p. 325-348.

RINDFLEISCH, A.; HEIDE, J. B. Transaction cost analysis: Past, present, and future applications. Journal of Marketing, v. 61, n. 4, 1997, p. 30-45.

ROSAMOND, Ben. Theories of European Integration. London: Palgrave Mcmillan, 2000.

RUSSELL, S. H. Supply chain management: more than integrated logistics. Air Force Journal of Logistics, v. 35, n. 3/4, 2011, p. 88-99.

RYNNING, Sten. Realism and the Common Security and Defence Policy. Journal of Common Market Studies, Oxford, v. 49, n. 1, jan. 2011, p.23-42.

SALES, R. D. Sistemas de Comando e Controle no Brasil - uma análise das contribuições do Exército Brasileiro. 2016. 164f. Dissertação (Mestrado em Ciências Militares) Programa de Pós-Graduação em Ciências Militares, Escola de Comando e EstadoMaior do Exército, Rio de Janeiro, 2016.

SILVA, G. C. Conjuntura Política Nacional: o Poder Executivo e Geopolítica do Brasil. 3. ed. Rio de Janeiro: J. Olympio, 1981.

SILVA, C. A. V; MUSETTI, M. A. Logísticas militar e empresarial: uma abordagem reflexiva. Revista de Administração, São Paulo, v. 38, n. 4, out./nov./dez. 2003, p. 343-354. 
STOCKHOLM INTERNATIONAL PEACE RESEARCH INSTITUTE (SIPRI). TIV of arms exports from the top 20 largest exporters 1989-2016. Disponível em: < http://armstrade. sipri.org/armstrade/page/toplist.php > . Acesso em: 28 abr. 2017.

STOCKHOLM INTERNATIONAL PEACE RESEARCH INSTITUTE (SIPRI). Military expenditure database, 2016. Disponível em < http://www.sipri.org/databases /milex > Acesso em: 04 outubro 2016.

THE INTERNATIONAL INSTITUTE FOR STRATEGIC STUDIES - IISS. The Military Balance 2009: the annual assessment of global military capabilities and defence economics. New York, 2009.

TRYBUS, M. Buying Defence and Security in Europe: The EU Defence and Security Procurement Directive in Context. Cambridge: Cambridge University Press, 2014.

UNIÃO EUROPEIA. Constituição (2004). Diretiva n ${ }^{0}$ 18, de 31 de março de 2004. Directiva 2004/18/CE do Parlamento Europeu e do Conselho: relativa à coordenação dos processos de adjudicação de determinados contratos de empreitada de obras públicas, dos contratos públicos de fornecimento e dos contratos públicos de serviços. Disponível em: < http://eur-lex.europa.eu/legal-content/PT/TXT/?uri = celex\%3A32004L0018 > . Acesso em: 19 set. 2017.

UNIÃO EUROPEIA. Constituição (2009). Diretiva nº 81, de 13 de julho de 2009. Directiva 2009/81/ce do Parlamento Europeu e do Conselho: relativa à coordenação dos processos de adjudicação de determinados contratos de empreitada, contratos de fornecimento e contratos de serviços por autoridades ou entidades adjudicantes nos domínios da defesa e da segurança, e que altera as Directivas 2004/17/CE e 2004/18/CE. Disponível em: < http://eur-lex.europa.eu/legal-content/PT/TXT/ PDF/?uri = CELEX:32009L0081\&from $=\mathrm{EN}>$. Acesso em: 03 jun. 2016.

UNITED KINGDOM. Ministry of Defence. UK and France strengthen defence cooperation. London: Ministry of Defence, 2014. Disponível em: < https://www.gov. uk/government/news/uk-and-france-strengthen-defence-co-operation $>$. Acesso em: 14 out. 2015.

UNITED KINGDOM. UK-France Summit 2010 Declaration on Defence and Security Co-operation. London: Crown Copyright, 2011. Disponível em: < https://www.gov.uk/ government/news/uk-france-summit-2010-declaration-on-defence-and-security-cooperation > . Acesso em: 23 jun. 2015.

UNITED STATES. Export.Gov. Security \& Defense Sector. 2017. Disponível em: < http://2016. export.gov/europeanunion/marketresearch/securityanddefensesector/index.asp > . Acesso em: 02 maio 2017.

VENESSON, Pascal; WIESNER, Ina. Process Tracing in Case Studies. In: SOETERS, Joseph; SHIELDS, Patricia; RIETJENS, Sebaastian (Eds.). Routledge Handbook of Research Methods in Military Studies. London: Routledge, 2014, p. 90-101. 
WALTZ, Kenneth N. Strutural Realism after the Cold War. IN: International Security, Vol. 25, No. 1, Summer 2000, pp. 5-41.

WALTZ, Kenneth N. Teoria das Relações Internacionais. Lisboa: Gradiva, 2002.

WALT, Stephen. Origins of Alliances. Ithaca: Cornell University Press, 1987.

WENDT, Alexander. Anarchy is what States Make of it: The Social Construction of Power Politics. International Organization, Vol. 46, No. 2, Spring, 1992.

YANG, H. et al. Arms or butter: The economic effect of an increase in military expenditure. Journal of Policy Modeling. ScienceDirect. Technology Management, Economics and Policy Program, Seoul National University, Republic of Korea. 2015. 